\title{
Computer assisted school administration and management: Where are we and where should we go?
}

Adrie J. Visscher

University of Twente, Faculty of Educational Science and Technology, Department of Educational Administration, P.O. Box 217, 7500 AE Enschede, The Netherlands

\begin{abstract}
In this paper the international state of the art of computer-assisted school administration and management (CASA) is presented. This is done by analyzing the developmental stages CASA has gone through, available school administrative computer applications, factors determining school information system implementation and the impact of system use. Finally, some reflections on the future of CASA are presented.
\end{abstract}

Keywords Codes: K.3.1, K.4.3, K.6.0

Keywords: Computer Uses in Education; Organizational Impacts; Management of Computing and Information Systems, General

\section{INTRODUCTION}

About two and a half year ago the Journal of Research on Computing in Education published a special issue on CASA [1], which was designed to document, on an international level, the status of computer usage in support of school administration.

One important reason for the special issue concerned the limited attention that CASA receives in the literature which is in strong contrast with the wide utilization of computer technology for the operation and management of schools. Until the literature had paid no attention to issues such as shortcomings of the available software, successful strategies for information system design, development and implementation, and the impact of the use of computers on the efficiency and effectiveness of administrative and management activities. Therefore, authors from Australia, England, Hong Kong, Israel, Mexico, the Netherlands and the United States [2] portrayed the developments and state of the art regarding CASA in their country. The last article of the special issue summarized some general developments and problems and pointed to future needs and required problem solving strategies.

The contents of the concluding article of the special issue, in combination with the results of additional empirical research, form the basis for this paper. 


\section{DEVELOPMENTAL STAGES}

The country-specific articles of the special issue led to Table 1.

Table 1

Time-frame for each stage of CASA development in seven countries (based on 1991 data).

\begin{tabular}{llll}
\hline & initiation & expansion & integration \\
\hline Hong Kong & end $70 \mathrm{~s}$ & early $80 \mathrm{~s}$ & not yet \\
Australia & early $80 \mathrm{~s}$ & mid $80 \mathrm{~s}$ & $' 85$ \\
Great Britain & '78 & '83 & '83 \\
Israel & till '85 & '85 & not yet \\
USA & end $60 \mathrm{~s}$ & '70s & '80s \\
Netherlands & mid 70s & end 70s & '85 \\
Mexico & '58-70 & $70 \mathrm{~s}$ & not yet
\end{tabular}

Some interesting general trends are certainly emerging, but one must recognize that large differences may exist between schools within a country. So, if an author observes a country as having attained a certain level of CASA, this is likely to mean that only some of the schools are at that level, in most cases only those that are leading in CASA.

Basically the same 'initiation picture' is observed in all countries. Teachers in the science subjects started to create the first school administrative software in an enthusiastic, but amateurish way. Some years later, software vendors entered this market producing their own software or adapting existing software to more professional standards.

The differences with regard to when countries entered the various CASA stages are striking. The U.S.A. clearly took a pioneering role in this area; the first applications were initiated there in the 1960s when the first school business applications (e.g., finance and pay-roll) were implemented. It took many of the other countries 15 to 20 years more to reach the same level of school administrative computing. Mexico has been in the initiation stage since the 1960s, but only for educational administrative computing at the central government level. Thus, administrative computing at the school level in Mexico has still to embark on the first developmental stage.

However, despite the differences between countries, in most, with the exception of Australia, initial school administrative computer applications had been developed by the end of the 1970s. Subseqently, during the expansion stage new applications were rapidly produced in these nations. The expansion stage occurred in the 1970s in the U.S.A. and the Netherlands, and in the 1980s elsewhere.

The integration phase can, succinctly stated, be characterized by 'integrated modules' and 'the production of management information' (such information was then considered valuable for the first time). By the mid-1980s four countries had progressed to the 
integration stage (Australia, Great Britain, the U.S.A., and the Netherlands). Israel, Hong Kong and Mexico have not yet reached that level of CASA; they are still in the expansion stage in which several loose, non-integrated clerical and administrative applications are being used. Therefore, computer-assisted management support may be limited in those countries.

During the stabilization stage the full potential of computer assistance gets accomplished to some extent, and attention therefore is directed to system maintenance and refinement. One gets the impression that none of the countries has truly reached this CASA stage because a number of applications (especially management subsystems) are still not available and full utilization of the potential of information technology is not a reality. For that reason the stabilization stage is not included in Table 1. Some countries, however, expect to enter the stabilization stage in the near future.

An interesting observation concerning the evolution of CASA is that a country like Australia, which until recently was lagging behind, has changed this situation dramatically in just a few years. Certainly with regard to the broad scale of CASA implementation Australia at this moment is one of the leading CASA nations. Since the mid-1980s, serious statewide (New South Wales) attention has been given to CASA through evaluating existing software, producing a new high-quality school information system, and supporting schools with system implementation. By 1992 more than 2200 schools will be using this standardized system! The Australian experience implies that if a nation decides to direct serious attention to CASA and if it is able and willing to commit the required resources, it is possible to change the state of practice dramatically in a few years.

Not only 'down under', but also in other countries a special project initiated by national or state government, or by a special project group, has provided the stimulus to enter a higher developmental stage. Israel had its PMIS project, Hong Kong the HKSAS, Great Britain the Local Management of Schools initiative, Holland its SCHOLIS project. In each case these projects have served to lift CASA to a higher level because they were directed toward the production of better school information systems and also stimulated vendors of other software packages to improve their products. If initiatives like these occur in a country, it is likely that the quality of CASA systems will evolve very much; on the other hand, if they do not occur then progress may be much slower.

The experience in Mexico shows how the lack of capable professionals, of finance and of a technical infrastructure for electronic data communication can limit the evolution of CASA. Technology can have a large potential, but when the professional expertise for the development of high-quality systems is not available, theoretically possible systems will not be realized.

\section{AVAILABLE APPLICATIONS AND THEIR USE}

It is difficult to judge accurately which applications have been realized, since the names of the applications in fact only tell us that software has been developed that provides support with activities in certain areas (e.g., finance, personnel, timetabling). What specific activities are supported and how this is done remains obscure. Nevertheless, the information that is presented demonstrates that some countries have progressed much further than others with respect to the number of applications developed.

In several countries a considerable number of registrational applications has been 
developed (e.g., in Australia, Great Britain, the USA and the Netherlands), but software modules that are directed specifically to the support of school managers (e.g., by providing management information or solving complex allocation tasks) are the Cinderella of the available applications.

The basic structure of a school information system limits or defines the extent of management assistance available. As modern tools such as relational database management systems (RDBMS) and query languages become available, high levels of management support become possible; the query language in combination with a RDBMS enables the definition of, and response to, questions in which school managers are interested.

The international IEA study concerning the use of computers in education [3] showed that CASA is less intensive in primary schools than in secondary schools. This might be because primary schools are less complicated with regard to timetables, data about financial matters, teaching staff, etc. However, this does not explain why about $50 \%$ of primary schools do not use word-processing. In general, it seems that although a large number of schools make use of the computer for at least some school administrative purposes, with the exception of word-processing, the majority of primary schools do not use applications like teacher registration, student registration, timetable construction, financial registration and library records.

The number of secondary schools that do not use administrative applications either is still considerable; student data and word-processing applications are found in the majority of secondary schools, but for almost all of the other applications $50 \%$ to $80 \%$ of the schools do not use them at all.

\section{FACTORS DETERMINING SYSTEM USE AND IMPACT}

In the lead article of the special issue of JRCE [2] the following model for the implementation of computer-assisted school information systems was presented.

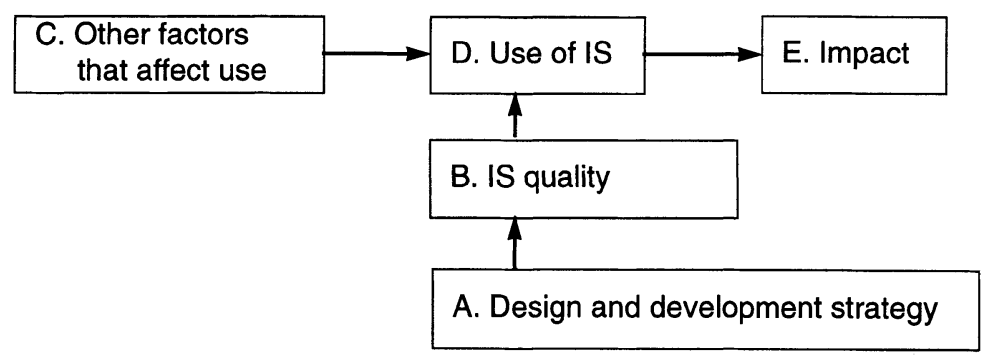

Figure 1: The relations between design, use and effects of ISs.

The degree and way of use of the information system (IS) is supposed to be determined by information system quality characteristics (which are expected to be influenced by the chosen design strategy) as well as by other factors like the nature of the implementation process and of the school organization in which the IS is implemented. Effects of system use are supposed to be a function of the intensity with which, and the way in which, an 
information system is used.

The information in the country-specific articles of the special issue generally supports the framework. However, it should be stressed that there proves to be little empirical research regarding the implementation and impact of SISs, and therefore clear understanding of the relationships between the variable groups is lacking. While the authors of the country-specific articles typically provided an opinion based on their own experience with CASA projects, it is evident that empirical studies on the framework are needed.

Each of the variable groups in the framework is discussed below, on the basis of the observations of the authors of the country-specific articles.

\subsection{The characteristics of the design strategy}

In most of the countries an evolution of the strategy used to design SISs can be identified. This strategy includes the automation goals, the way in which system analysis and definition was carried out, and how the standardization/flexibility problem (to develop an IS that is standardized and flexible enough to be used in large groups of schools) was addressed. Table 2 summarizes this development process.

Table 2

The evolution of design strategies.

\begin{tabular}{|c|c|c|c|}
\hline designers & goals & $\begin{array}{l}\text { approach for } \\
\text { analysis }+ \text { definition }\end{array}$ & $\begin{array}{l}\text { standardization } \\
\text { flexibility }\end{array}$ \\
\hline teachers & efficiency & $\begin{array}{l}\text { - application directed } \\
\text { - expert } \\
\text { - decentralized }\end{array}$ & - tailor-made \\
\hline $\begin{array}{l}\text { software } \\
\text { vendors }\end{array}$ & efficiency & $\begin{array}{l}\text { - more integration } \\
\text { - expert } \\
\text { - central }\end{array}$ & - standardization \\
\hline $\begin{array}{l}\text { special } \\
\text { projects }\end{array}$ & effectiveness & $\begin{array}{l}\text { - fundamental } \\
\text { - participative } \\
\text { - central }\end{array}$ & - compromise \\
\hline
\end{tabular}

During the initiation and expansion stages teachers developed school administrative computer applications with the goal of improving the efficiency of school office activities.

The strategy used in the analysis of the school organization and the design of computer applications was not very professional, which was due in part to the fact that activities like these were new and knowledge concerning the development of SISs was limited everywhere. The strategy might be labeled 'first things first'. A teacher-designer would observe a valuable opportunity for using the computer (mostly in the area of pupil registration), subsequently started to analyze these school activities and developed software that could assist there. The approach was application-directed: one or two independent applications would be identified, then another one, after that yet another one, etcetera. The teachers who pioneered this were the experts in their schools, and their power and autonomy were 
considerable. Since the applications were developed by teachers for their own schools, the software was developed in a decentralized way. As a result SISs were tailor-made for the school in which they were developed. Therefore, these were neither generalized systems nor very flexible.

After these pioneering activities software vendors began to enter the CASA-arena. Just like the pioneer teachers before them their design goal was to increase the efficiency of registrational activities.

System analysis often remained limited to a few schools, and subsequently, the IS was adapted on the basis of experience of the other schools that were using it. The strategy that was followed can be characterized as more integrated: not purely directed toward developing a single application, but giving some consideration to relations among several applications. Nevertheless, complete integration was a distant goal.

Just as in the case of teachers-as-designers the vendor software developer played the expert role and user-participation was limited. Although designers of course listened to users, software specialists to a great extent determined themselves what the software would look like. An important difference between vendors and teacher software developers is that the former do not develop SISs for only one school. In fact they try to develop a SIS that can be used in as many schools as possible. This has implications for the system development approach and the way in the which the standardization/flexibility problem is handled.

As a result of the centralized approach, standardized systems are created for many schools, which means that schools have to adapt themselves to the characteristics of these systems. As discussed before, this may cause problems for schools.

The third group of SIS designers is formed by those who initiate a project that aim to product a new generation of SISs. A central feature of these projects is that they strive for better systems, after experience has been gained in the first two stages of CASA. These designers consider school effectiveness as an important goal of automation, in addition to school efficiency. It becomes clear that types of support such as management assistance and computer-assisted data communication within the school and between schools and other institutions can be achieved through computer use. Thus, the goal is to realize in a systematic way all possible useful forms of computer support.

To realize this goal, a fundamental design strategy [4] should be chosen in which designers are aware that the first step is to draw a picture of the entire school in terms of information flow and information demands. Once this picture is available and when the relations among information flows are clear, it then becomes possible to design the architecture of the entire system, resulting in an information system framework. Subsequently, individual modules from the SIS-framework are developed in a stepwise manner.

This group of designers is aware of the importance of user participation and extensively involves users in system design. For this reason the role of computer science experts is balanced by the influence of users. These systems are created centrally and are planned to be used in as many schools as possible.

The fact that system development is not done for only one or a limited number of schools, but centrally, for a large number of them, implies that a standard system is produced. Fung [5] observed that standardization is required with central SIS-development because of the high costs of system design, development, user support, and system maintenance. 
While schools will not receive tailor-made SISs, it is tried wherever possible to build flexibility into their IS. Through this a compromise between standardization and flexibility is achieved. The modular structure of the SIS enables schools to choose and use only those modules they need, and options within modules are used to create additional flexibility. Use of modern software tools (RDBMS, query languages) also provides flexibility, since every user can potentially retrieve ail information he needs.

Although the fundamental approach to system design can be observed in a number of countries it is not yet widespread, the majority of countries having not yet achieved this level of system development. Nevertheless, if a country wants to develop a CASA capability, it should start with the fundamental, participative and centralized approach. The cost and effort invested will rapidly return the investment, because the system developed is likely to result in the desired improvement of school efficiency and effectiveness.

\subsection{Information system quality}

One of the most important prerequisites for successful implementation of school information systems is, of course, a high-quality SIS. In none of the countries the quality of the available SISs has been systematically studied. As a result, it is not clear how and to what degree the system features may have influenced then implementation. This is regrettable since insight in the variables that determine SIS-quality can help to create better quality systems. What probably happens now -in the best case- is that a SIS is developed, implemented and subsequently adapted on the basis of user feedback, and this process continues until users 'feel OK'. However, this does not necessarily mean that they are fully satisfied or that they use the system to its full potential.

Some authors stated that the ideal software (user-friendly, reliable, offering strong support to users, etc.) still was not available in their countries. Probably this is also true for other countries, because producing high-quality software requires considerable time, for thorough analysis and design, for carefully introducing the systems into schools, and for systematically collecting user feedback to maintain and enhance software. In most countries insufficient time has been invested in these activities. Nevertheless, IS-quality gradually increases as a result of improved system analysis and definition, software development tools (RDBMS, software generation tools, data dictionaries), and user feedback.

\subsection{Other factors that influence implementation: Features of implementation pro- cesses and school organizations}

'People variables' prove to be crucial anywhere. Motivation for, and attitude about, the innovation were mentioned very frequently, as was the extent to which future users can influence the process of development and implementation.

On the basis of seven case studies in pioneer schools Visscher [6] concluded that the innovation process first raises a variety of problems, among other things as a result of vague goals and inadequate planning. The limited resources may cause those who are responsible for implementing the innovation to be overloaded. After some time, however, most of the problems seem to get solved and school (office) life returns to routine.

Many authors stress that careful management of the innovation process is essential. The procedural side of the innovation process is crucial: It is important to establish clear innovation goals and a realistic innovation pace. Schools need time to learn to appreciate and assimilate an application. A gradual, 'stepping stone' implementation of a modular 
SIS therefore is viewed as the best way to innovate in this field.

Bird [7] and Fung [5] stressed that when a project champion encourages the innovation, the chances of successful implementation are much greater; the same applies to the extent to which school management encourages and supports the innovation.

Bird [7] pleas for school-based project teams that consist of a number of staff members; knowledge about CASA then is dispersed among staff, which means that if one of them leaves the school this will not cause big problems for the continuation of CASA within the school.

The introduction of SISs has made it clear that the training of users is essential and that this usually receives far too little attention. Training often proves to be too technical, or else it does not focus on how the system is intended to support users in their various management responsibilities. User-training is important to teach users how to use hardware and software, as well as data produced by an IS. The latter training is connected to questions like 'What do data mean?' and 'How can one use reports produced to make decisions?". Although answers to this type of questions are very important, they frequently receive very little attention.

Some authors noted that schools that operated well before computer introduction also were more successful in implementing an innovation. This may suggest that if a school has problems, the introduction of the computer is not likely to solve these problems. In fact it is very probable that the implementation process will exacerbate existing problems.

\subsection{Degree and way of information system use}

An important finding is that SISs in almost all countries are used to support clerical activities. Routine office work that formerly was done manually now is carried out by means of the computer. Support of school management activities, however, is very limited. This may be the result of the fact that in most countries relatively few management applications have been developed, or it might be a consequence of the characteristics of schools and of the way school managers choose to operate. It was already observed that little empirical evidence has been collected on the impact oi school organizational factors, and it is unclear as to what extent school managers really are in need of management information and what type of computer support they would like to receive. It might be for instance, that applications that help them solve complex allocation problems (e.g., timetabling) will be used much more extensively than software that provides managers with information that serves as a basis for policy development. Schools often are considered to be 'professional bureaucracies', in which teachers operate very autonomously and policy development and implementation therefore are difficult, especially when teacher autonomy is threatened.

The results of a recent study by Visscher [8] showed that providing a school with a computer-assisted school information system which can generate valuable management information does not mean that school administrators automatically will benefit from this opportunity. Almost all schools studied used the system for daily, routine absenteeism registration activities. Very little use was made of the potential to analyze absenteeism data and look for trends and relations among relevant data elements (e.g., when pupils play truant, whirh subjects or teachers have greater absenteeism rates).

One plausible reason for this may be that schools need more training to develop their computer-assisted policy-making capacity. Schools that want to use the computer for this purpose, need to be able to: 
- decide which information they need for decision-making and would therefore like to retrieve from the system;

- retrieve data by means of a menu or a query language;

- interpret retrieved data in such a way that the resulting information can be used for decision-making;

- use the information to develop, implement and evaluate school policy.

The second and third conditions may be regarded as technical and thus require some training in data retrieval and interpretation. The first and last mentioned skills are probably harder to realize. It has already been indicated that schools in general are not considered strong policy-makers and evaluators and that installing a computer-assisted system will not automatically transform them into either. Evaluating school processes critically, detecting problems and causes (if possible) and trying to design, implement and evaluate remedies, requires organizational development often. This may well be a lengthy procedure and demands energy from schools and from those who support them. It would be interesting to investigate whether it is possible to train schools in the skills that are a prerequisite for computer-supported policy-making and, if so, which training characteristics are the most successful.

\subsection{System use effects}

Very little research has been carried out on the positive and negative effects of SIS-use. Many authors anticipate certain positive effects (e.g., better registration work, better decision-making), but strong empirical evidence for these effects is lacking. None of the authors observes an improvement of the quality of schooling and teaching, or an impact on the school organizational structure as a result of school administrative computing.

In the IEA-study on computer use in education [3] respondents from many countries were asked whether they thought school administrative computer use had led to positive or negative effects. A range of positive effects was strongly perceived to have occurred, including improvement in:

- $\quad$ quality of pupil administration

- information available

- quality of teacher administration

- efficiency of school administration

- other organizational aspects

Other positive effects were perceived less strongly, including improvement in:

- the evaluation of policy effects

- the time needed for absentee registration

- information on pupil achievement

- the allocation of students to groups

- timetable quality

- time needed for timetable construction

Relatively few negative effects were mentioned by respondents and those that were observed were mentioned by very few respondents. 


\section{THE FUTURE OF CASA}

Plans for the future of CASA vary. In quite a lot of countries further development of (management) applications is an important goal. Development of sophisticated decision support systems and further integration of databases and educational and administrative computer applications is planned in countries that are very active in the field of CASA. The government is frequently involved in this activity and usually plans a wider implementation of professional SISs in schools.

Establishing local area networks within schools and linking them with other schools, districts and governmental ISs is another frequently mentioned plan, as well as providing schools/users with (more) intensive implementation support.

Should a country desire to utilize information technology for school administrative support, a fundamental approach is recommended:

1. A careful analysis of schools and their environmental interaction, to find out what information is valuable for executing the various organizational activities.

2. Design of information systems at central (state or national) level. Future users should be involved in these design activities so as to explain their potential information system needs. An information system framework (ISF) should be designed, containing a complete definition of all (clerical and management) required capabilities that can be obtained from modern information technology to support the needs of the school.

3. Software should be generated for each ISF-module and the desirable implementation strategy be defined carefully, taking into account:

- the logistic aspects of introducing a SIS into schools: e.g., the prerequisites for data entry, and the adaptation of school procedures;

- the need to train users adequately (information management being an important training topic);

- the need for a project team at school level to back up for the school CASA-expert should he leave. Moreover, a project team can facilitate implementation by motivating users and planning and coordinating the required activities carefully, and

- the capacity of schools to adopt, implement and incorporate an innovation. A gradual 'stepping stone' approach is required; only after a school has incorporated an information system module introducing the next module can be considered.

The role of the government should be an active one from the start, since the market for SISs often is not commercially interesting enough for software vendors. The construction of high quality SISs requires too high an investment in relation to its potential revenues.

Strong governmental support is also of importance for the government itself, since the use of professional ISs can improve the quality of school management, which is especially valuable with regard to the initiatives to devolve competences from central governmental level to school level. As a result schools become more autonomous, and have to develop and evaluate school policy in areas previously under responsibility of the government. School information systems can be a powerful tool for more autonomous schools who need information on which to base their policy-development and evaluation. However, the potential role of these systems should be placed in perspective.

Information use within organizations is complicated. The link between the information collected and the problems faced may be weak. Sometimes information is used to justify decisions already made and information collection is focused on the measurable. 
Moreover, managers heavily rely upon verbal, face-to-face information, rather than on formal (e.g., computer-assisted) reporting. They only partly behave like rational, informed problem-solvers. Decision-making is often done over brief periods of time, and getting information rapidly can be more important than getting absolutely right information. That management information must be tangible and address specific problems also puts managers' use of aggregated computer information in perspective. In connection with this Sproull and Zubrow [9] stress the importance of behaviourally grounded information systems, consisting of many modes of information collection (including informal modes), sources, (e.g., students, parents, teachers) and varying forms of information use (problem solving, symbol management). Since only part of the required information can be produced by the computer, other ways of data collection and processing, including nonrational ones, should be used as well.

The usage of computerized information systems is also influenced by some organizational features of schools. Schools are nog considered to be very decisive policy-makers. Decisions are often off, or do not solve a particular problem, and the link between decisions and their execution is weak. A school's policy making capacity influences the degree to which it will benefit from computer data. Although SISs certainly can be of importance in policy-making, these organizational characteristics imply that policy-making and -execution will also be difficult in a computerized situation.

A final remark concerns research in the field of CASA. We are in need of systematic, empirical research, not only because of its scientific value but also to be able to improve the practice of school administrative computing. Hopefully, future studies will increase the body of knowledge about this field and enable us to utilize fully the potential of CASA in making school administration and school management more effective.

\section{REFERENCES}

1. Visscher, A.J., Spuck, D.W. \& Bozeman, W.C. (Eds.), (1991). Computer Assisted School Administration and Management: An international Analysis. Special issue of the Journal of Research on Computing in Education.

2. Visscher, A.J. (1991). School Administrative Computing: a Framework for Analysis. Journal of Research on Computing in Education, 24(1), 1-19.

3. Pelgrum, W.J. \& Plomp, Tj. (1991). The use of computers in education worldwide; results from the IEA Computers in Education survey in 19 educational systems. Oxford: Pergamon Press.

4. Fung, A.C.W. (1988). Trends on development in computer-aided school administration. Proceedings Microcomputers in Education Conference. Hong Kong, A-20 A-28.

5. Fung, A.C.W. (1991). Computer Assisted School Administration in Hong Kong. Journal of Research on Computing in Education, 24(1), 120-145.

6. Visscher, A.J. (1988). The computer as an administrative tool: Problems and impact. Journal of Research on Computing in Education, 21, 28-35.

7. Bird, P. (1991). Computer Assisted School Administration in England. Journal of Research on Computing in Education, 24(1), 20-39.

8. Visscher, A.J. (1992). Design and evaluation of a computer-assisted management information system for secondary schools. Enschede: Universiteit Twente, Toegepaste 
Onderwijskunde.

9. Sproull, L.S. \& Zubrow, D. (1981). Performance information in school systems: perspectives from organization theory. Educational Administration Quarterly, 17(3), 61-79. 